\title{
The evaluation of the regularity of the combustion process in the SI engine fueled with petrol and ethanol
}

In the paper are presented results of a research work concerning automotive spark ignition engine fueled with ethyl alcohol. The research was performed on a Fiat 1100 MPI engine adapted to dual fuel feeding. Injection of ethyl alcohol was accomplished in area near inlet valve with use of original injectors, the same as used in case of gasoline feeding. The subject-matter of the study was to compare smoothness of engine operation fueled with alcohol in relation to parameters of the engine fueled traditionally with gasoline. There were analyzed combustion parameters calculated on the basis of recorded indicated diagrams of successive individual combustion cycles and averaged diagrams of successive 50 cycles. Performed investigations are pointing at smooth engine operation running on neat alcohol, and on improvement of performance parameters such as effective power and overall efficiency.

Key words: ethyl alcohol, overall efficiency, engine smoothness, combustion pressure, indicated pressure

\section{Introduction}

Obligation of usage of biofuels results from accomplishment of the National Indicative Targets (NCW in short), which assume gradual increase of reproducible fuels in total volume of engine fuels [1-3]. According to decree of the Polish Government on the NCW of the 20.07.2013, energetic fraction of biofuels in the year 2017 should amount to $7.8 \%$, while in the year 2018 should reach level of $8.5 \%$ [3].

The alcohols belong to primary biofuels (used mainly in spark ignition engines) and esters of unsaturated fatty acids used to fueling of self-ignition engines [5-8].

Simple alcohols, like methyl and ethyl, can be produced from a biomass, reproducible source of energy, possible to be obtained in very high quantities [9, 12]. Ethyl alcohol can be obtained in fermentation process of vegetable raw materials (cereals, potato, sugar cane, cassava) and cellulose from a wood waste. It seems that in future, in Polish domestic conditions, methyl alcohol produced from coal or natural gas can also play an important role [13, 14, 18]. A future can be foreseen also for developed during the recent years technology of synthesis of methanol from carbon dioxide and hydrogen.

Products of combustion of methyl and ethyl alcohols are carbon dioxide and water, while the process proceeds according to the following reaction:

$$
\begin{gathered}
\mathrm{CH}_{3} \mathrm{OH}+\frac{3}{2} \mathrm{O}_{2} \rightarrow \mathrm{CO}_{2}+2 \mathrm{H}_{2} \mathrm{O} \\
\mathrm{C}_{2} \mathrm{H}_{5} \mathrm{OH}+3 \mathrm{O}_{2} \rightarrow 2 \mathrm{CO}_{2}+3 \mathrm{H}_{2} \mathrm{O}
\end{gathered}
$$

Mass fraction of carbon atoms in a molecule of alcohols is lower comparing to traditional fuels and amounts to 0.375 for methyl alcohol, and to 0.520 for ethyl alcohol, while in case of gasoline and diesel fuel such ratio amounts approximately to $0.845-0.850$. Anyhow, taking into consideration differences in calorific values, obtainment of the same unit of energy from alcohols will result in a slight, within limits $2 \%$, reduction of $\mathrm{CO}_{2}$ emissions comparing with gasoline [14-16].

Alcohols, due to their perfect properties, mainly due to high octane number, high heat of vaporization and high combustion rate, can be successfully used both in spark ignition engines (as a neat fuels, or as additions to traditional fuels), and in self-ignition engines as additions combusted simultaneously with diesel oil $[10,11,17,19]$. Advantages of alcohols have resulted in research studies on feeding of engines with alcohols, conducted in many worldwide research centers.

Spark ignition engines in European conditions are the most often fueled with mixtures of anhydrous ethyl alcohol or its esters with gasoline $[1,14,18]$. Due to susceptibility of alcohol-gasoline mixtures to stratification in low temperatures and in presence of water, total contents of alcohol or duration of usage of the mixtures are limited. Due to such reasons, fueling of spark ignition engines with pure ethyl alcohol is especially attractive, because in such case it is possible to use water-down alcohols, and cost of their production is lower. Fueling with pure alcohol enables to take full advantage of high knock resistance of alcohols, allowing increase of compression ratio, increase of overall efficiency and unit power of the engine [15, 18, 19]. Such direction is especially developed in Brasil, where are running some 2 million cars fueled with ethyl alcohol produced from cassava and sugar cane [14].

Common usage of multipoint injection of light fuels has created a new possibilities of usage of alcohol additive to gasoline, or alternating use of alcohol or gasoline to feeding of engines. After some modifications of engine's feeding system, start-up of the engine and its heating can occur when the engine is fed with neat gasoline, and further engine operation can occur with alcohol fueling. In such engines the compression ratio can be increased with 2.0-3.0 units, what should increase engine efficiency. The research studies show that also in area of partial engine loads, efficiency of the engine fueled with neat alcohol is higher, what have a significant effect in case of automotive spark ignition engines operated in urban conditions.

In this study are presented results of investigations of automotive engine of the FIAT 1100 MJT type fueled with ethyl alcohol. Special attention was paid on parameters of combustion process, calculated on the basis of recorded indicated diagrams from successive cycles of individual combustion courses and averaged diagrams for 50 succes- 
sive cycles. Selected parameters were used to assessment of smoothness of engine operation in successive cycles, so called cycle by cycle, and to assess changes in pressure course during combustion. As a reference values were implemented the same parameters as obtained during engine fueled with neat gasoline.

Performed investigations are pointing at a stable operation of the engine running on pure alcohol, and improvement of operational parameters such as effective power and overall efficiency.

\section{Engine test bed}

The investigations were performed on four cylinder, spark ignition engine with multipoint fuel injection of the Fiat 1100 MPI brand. Technical data of the engine are specified in the Table 1.

Table 1. Technical data of the Fiat 1100 MPI engine

\begin{tabular}{|l|c|}
\hline Engine type & Fiat $1100 \mathrm{MPI}$ \\
\hline Bore $\mathrm{x}$ stroke & $70 \times 72 \mathrm{~mm}$ \\
\hline Swept capacity & $1108 \mathrm{ccm}$ \\
\hline Compression ratio & 9.6 \\
\hline Rated power/rpm & $40 \mathrm{~kW} / 5000 \mathrm{rpm}$ \\
\hline Maximal torque/rpm & $88 \mathrm{Nm} / 3000 \mathrm{rpm}$ \\
\hline
\end{tabular}

Factory made engine was adapted to the dual fuel feeding with gasoline and alcohol. To perform it, in suction manifold of the engine were installed additional injectors for each cylinder. Original injectors (positioned close to inlet valve) served to injection of alcohol, while additional injectors to injection of gasoline. In course of the investigations, due to alternating fueling with alcohol or gasoline, were used original injectors only, positioned near the inlet valve. Scheme of prototype suction manifold is presented in the Fig. 1.

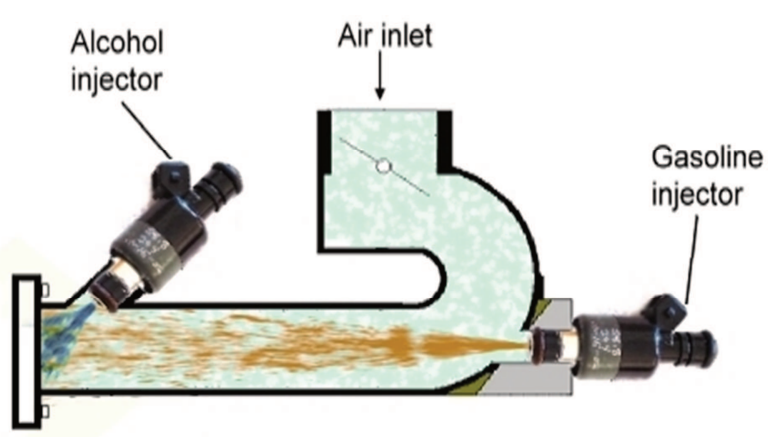

Fig. 1. Scheme of prototype inlet manifold of Fiat 1100 MPI engine

For the purpose of engine indication, in cylinder head of the second cylinder one drilled a hole for adapter of notcooled sensor made by the AVL. To recording of quickchanging pressures in the combustion chamber one make use of the INDIMETER 619 system made by the AVL.

In the test stand one installed a system to automatic acquisition of measurement data to the Excel calculation sheet. To needs of the testing, in the test stand one installed a dual system of fuelling for the alcohol and for the gasoline. Each from the systems was equipped with individual fuel pump and pressure stabilization system, and system to measurement of fuel consumption. Fuelling system enabled control of instantaneous consumption of the fuels, what considerably facilitated selection of engine adjustment and recording of time of consumption of a determined dose of the fuel. View of the test stand is presented in the Fig. 2.

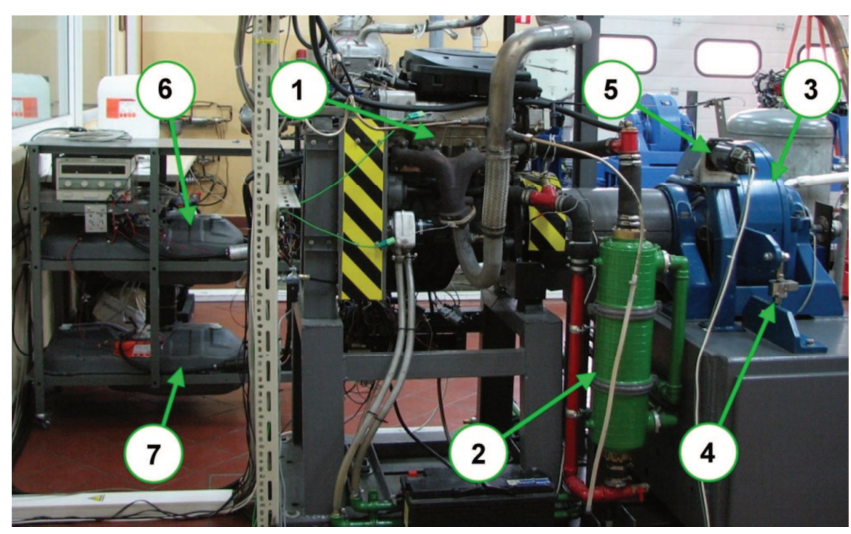

Fig. 2. Test stand - general view: 1 - research engine of Fiat 1100 MPI type, 2 - radiator, 3 - eddy-current engine brake made by Schenck, 4 - transducer of engine load, 5 - engine speed sensor, 6 - alcohol tank, 7 - gasoline tank

\section{Analysis of results of the investigations}

Comparison of overall efficiency of the engine shown in the Fig. 3 indicates what in complete range of engine loads the efficiency, when fueled with ethyl alcohol, was higher than efficiency of gasoline fueling. Especially significant differences are present in area of medium and maximal engine loads, where increase of the efficiency in range of $1.5-2.5 \%$ of absolute values was observed.

a)

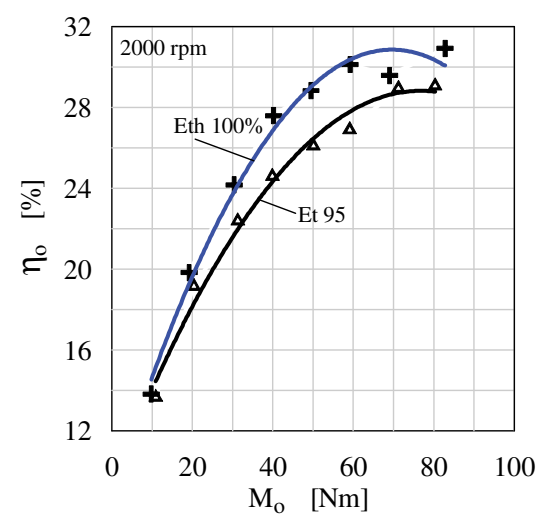

b)

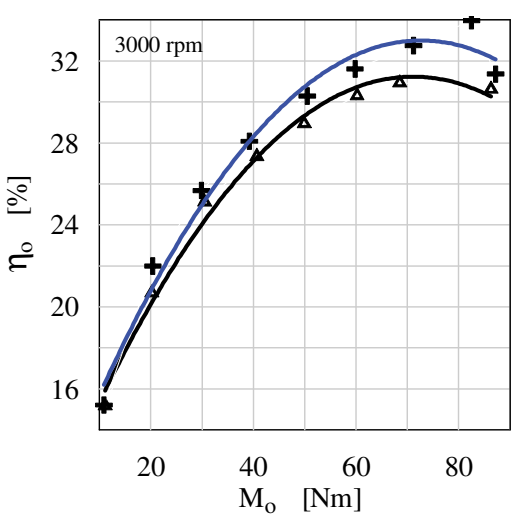

Fig. 3. Comparison of overall efficiency of the Fiat 1100 MPI engine fueled with Et 95 gasoline and ethyl Eth $100 \%$ alcohol 
a)

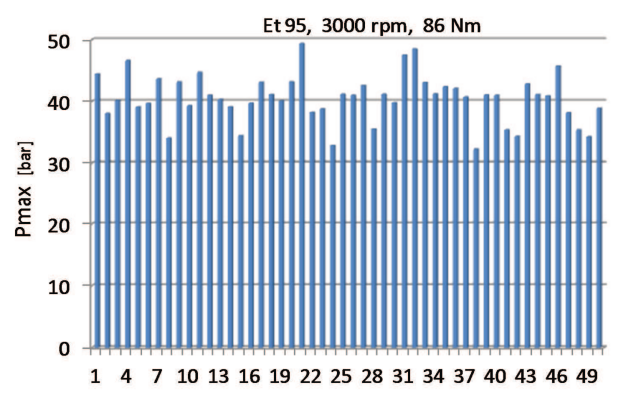

c)

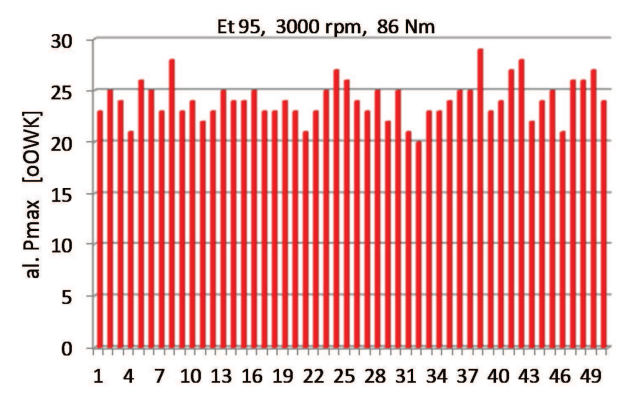

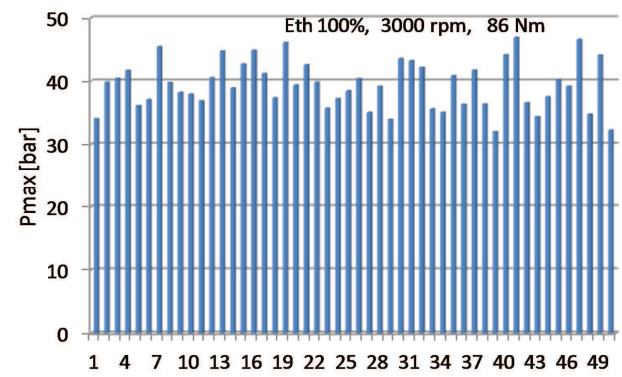

d)

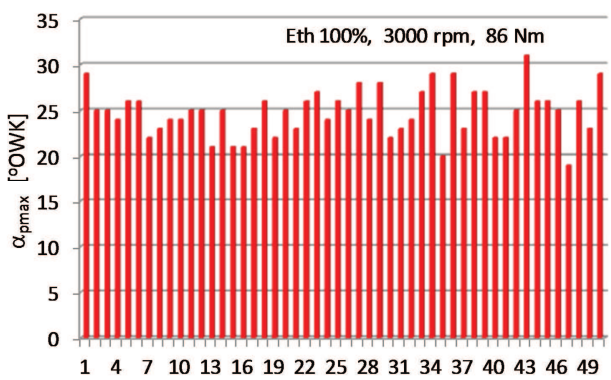

Fig. 4. Comparison of maximal combustion pressures and angles of their occurrence in the Fiat 1100 MPI engine fueled with Et 95 gasoline and Eth $100 \%$ alcohol

In the Figure 4 is presented comparison of maximal combustion pressures and CR angles corresponding with points of maximal pressure for 50 successive cycles of engine operation for the both types of fueling. From analysis of the Fig. 4 is seen that at full engine load the levels of maximal pressure for gasoline and alcohol are similar. Simultaneously, it can be seen a slightly bigger fluctuations of maximal pressure in case of gasoline, Fig. 4a.

In majority of cycles, maximal combustion pressures are developed for the angles of $20-25^{\circ} \mathrm{CR}$ after TDC, Fig. 4c and $4 \mathrm{~d}$. However, there are existing cycles in which the maximal pressures were developed later, while in case of ethyl alcohol such phenomenon occurs in distinctly bigger number of cycles, Fig. 4 d.

Values of average maximal pressures for 50 successive cycles of engine operation for changing engine loads are shown in the Fig. 5a. The average pressures were calculated according to the following dependency:

$$
\overline{\mathrm{p}}_{\max }=\frac{\sum \mathrm{p}_{\max -\mathrm{i}}}{\mathrm{n}}
$$

where: $p_{\text {max-i }}$ - maximal pressure of a successive cycle, $\mathrm{n}$ - number of analyzed cycles.

From comparison of the Fig. 5a results that in complete range of engine loads change, similar values of mean pressures are present for the both fuels. Such tendency was also seen for other investigated rotational speeds.

As a repeatability measure of successive operational cycles are used standard deviation of maximal combustion pressures and variability factor calculated from the following equations:

$$
\sigma_{\mathrm{P} \max }=\sqrt{\frac{\sum\left(\mathrm{p}_{\max -\mathrm{i}}-\overline{\mathrm{p}}_{\max }\right)^{2}}{\mathrm{n}-1}}
$$

$$
\mathrm{s}_{\mathrm{p}}=\frac{\sigma_{\mathrm{P} \max }}{\overline{\mathrm{p}}_{\max }}
$$

where: $\sigma_{P \max }-$ mean standard deviation, $\mathrm{s}_{\mathrm{p}}$ - pressure variability factor.

a)

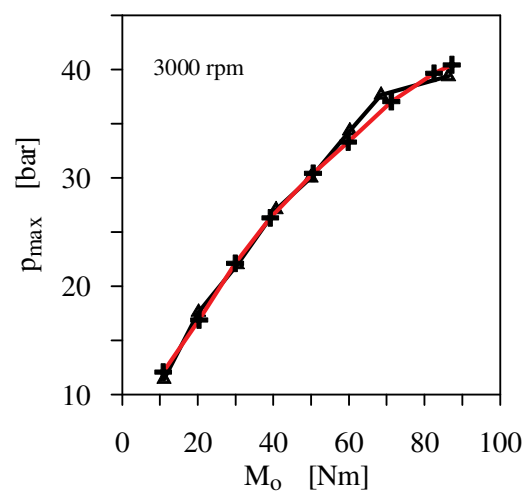

b)

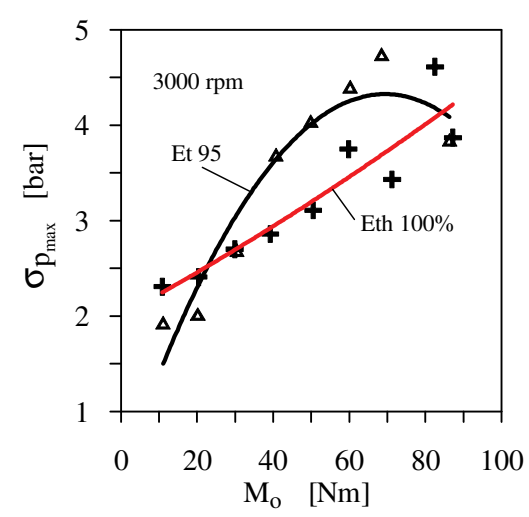

Fig. 5. Comparison of average value of maximal combustion pressures and mean standard deviation of combustion pressures in the Fiat 1100 MPI engine fueled with Et 95 gasoline and Eth 100\% ethyl alcohol 
Comparison of standard deviation values shown in the Fig. 5b and comparison of pressure variability factor shown in the Fig. 6 indicate that the engine fueled with ethanol in range of medium and maximal engine loads is characteristic of a higher repeatability of operation from one cycle to another. It speaks for more uniform and stable operation of the engine with such type of fueling, comparing with standard fueled with gasoline. Only in area of the lowest engine loads are present more bigger fluctuations of the pressure, what can be caused by reduction of temperature of the charge, connected with a higher heat of vaporization of alcohol and prolonged time of flame stabilization after ignition.

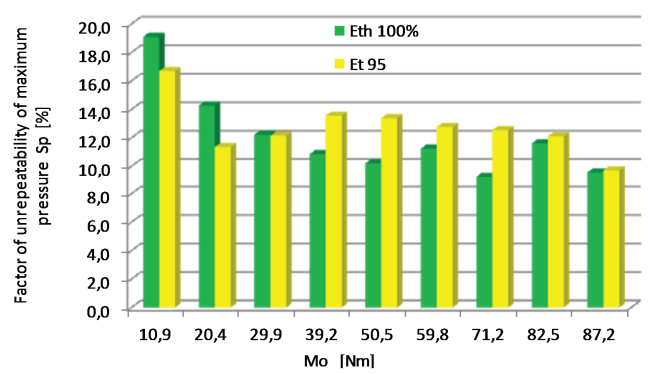

Fig. 6. Comparison of variability factor of maximal combustion pressures in the Fiat 1100 MPI engine fueled with Et 95 gasoline and Eth 100\% ethyl alcohol

Noisiness of engine operation when fueling with gasoline and ethyl alcohol is similar, what can be proved by similar values of pressure growth rate dp shown in the Fig. 7. In the both Figures $7 \mathrm{a}$ and $7 \mathrm{~b}$ are seen, in case of the both fuels, a distinct differences of the dp in range of 1.0-1.3 $\mathrm{bar} / \mathrm{ms}$ with maximal values of the $\mathrm{dp}$ amounting to 1.8 $\mathrm{bar} / \mathrm{ms}$. It is worth to pay attention on lack of distinct correlation of the runs with minimal growths of the pressure dp and with $\mathrm{CR}$ angles of the maximal pressure shown in the

a)

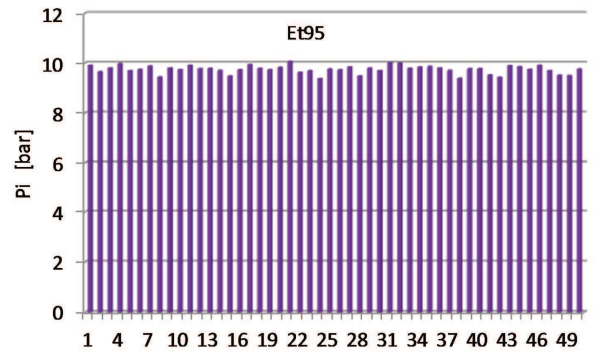

c)

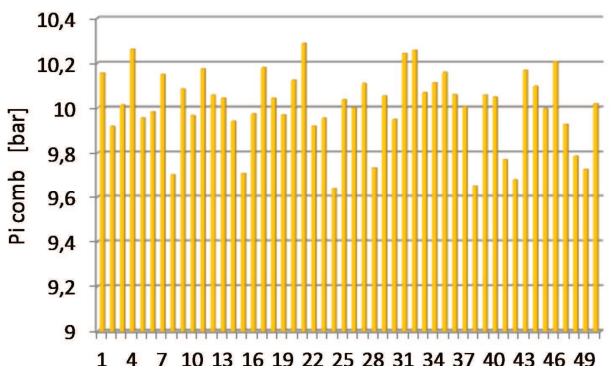

Fig. $4 \mathrm{c}$ and $4 \mathrm{~d}$. It suggests changing combustion rate of the charge after ignition, similar for the both fuels, which character is clearly stochastic.

The mean indicative pressure was calculated from the following formula:

$$
\mathrm{p}_{\mathrm{i}}=\frac{1}{\mathrm{~V}_{\mathrm{d}}} \int_{0}^{720} \mathrm{p} \frac{\mathrm{dV}}{\mathrm{d} \alpha}
$$

where: $\mathrm{p}_{\mathrm{i}}$ - mean indicated pressure, $\mathrm{V}$ - cylinder volume, $\mathrm{p}$ - instantaneous pressure of the working medium in cylinder.

a)

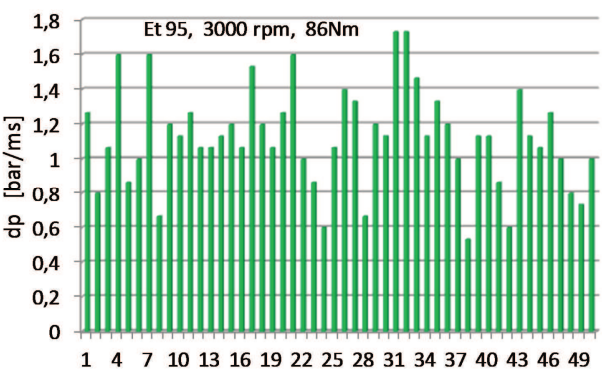

b)

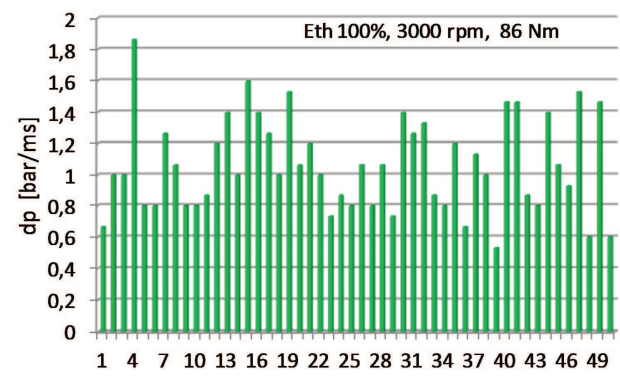

Fig. 7. Comparison of pressure growth rate during combustion on the Fiat 1100 MPI engine fueled with Et 95 gasoline and Eth 100\% ethanol

b)

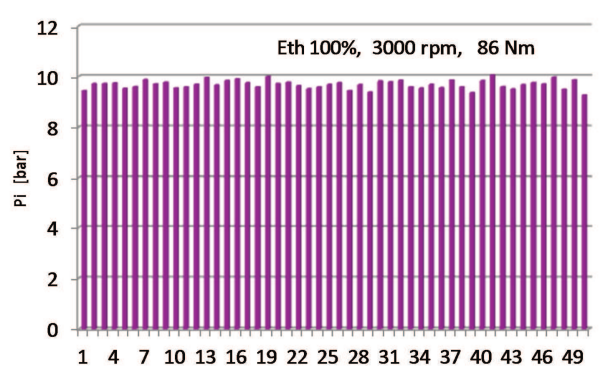

d)

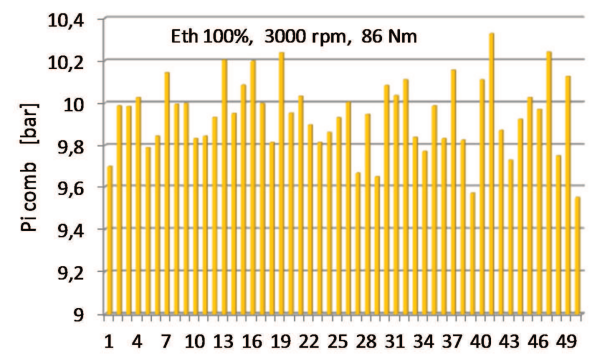

Fig. 8. Comparison of changes of mean indication pressure of complete cycle of $\mathrm{p}_{\mathrm{i}}$ and high pressure portion of the cycle $\mathrm{p}_{\mathrm{i}}$ comb in the Fiat $1100 \mathrm{MPI}$ run on Et 95 gasoline and Eth 100\% ethylene alcohol 
From comparison of the pressures shown in the Fig. 8a and $8 \mathrm{~b}$ is seen that at constant engine load, fluctuations of the pi in successive cycles of engine operation are very low and are similar for the both fuels. Analysis of relative factor of variability of the $p_{i}$ shown in Fig. 9 tells that in range of medium and maximal engine loads the fluctuations of pi for the both fuels are similar and their values are lower than $2 \%$, what should be considered as a small changes, comparing with the ones met in a spark ignition engines.

A little bit higher values of the fluctuations are present for the mean indicated pressures of high pressure portion of the cycle pi comb (calculated from the formula (6) only for $\mathrm{CR}$ angles for which instantaneous pressure in the cylinder is higher than atmospheric pressure $p>p_{a}$ ), because their values can approach to $6 \%$ of the mean value. Also in such case, however, value and character of the changes are similar for the both fuels.

Comparison of pressure runs for individual cycles during combustion of gasoline and ethyl alcohol is presented in the Fig. 10. With black colour are marked runs with maximal pressure similar to the mean value calculated from 50

a)

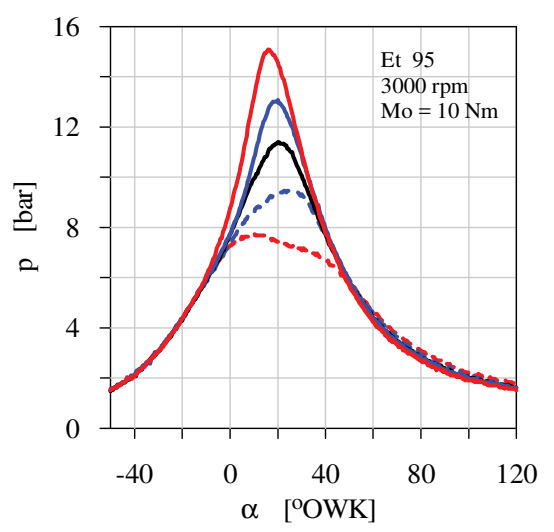

c)

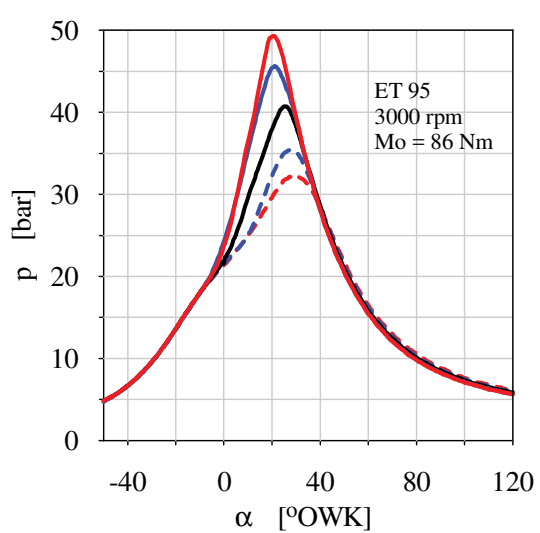

successive cycles of engine operation, while with dotted lines are depicted runs of the maximal pressures lower than the mean pressure, and with solid lines are depicted maximal pressures higher than the mean pressure. The comparisons were made for low engine load $\mathrm{M}_{\mathrm{o}}=10 \mathrm{Nm}$ and the load closer to the maximal one $\mathrm{M}_{\mathrm{o}}=86 \mathrm{Nm}$.

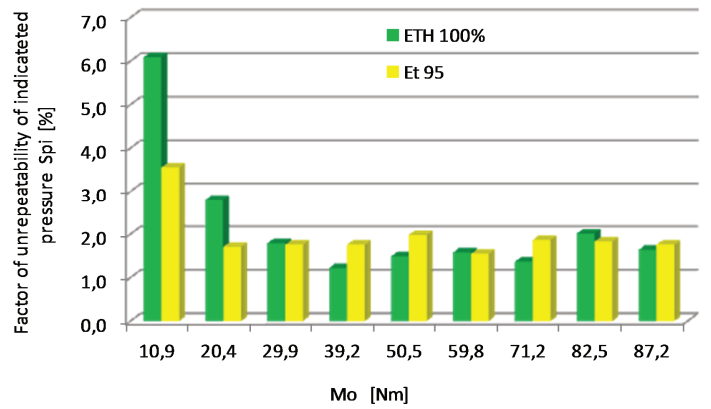

Fig. 9. Comparison variability factor of mean indicated pressure in the Fiat 1100 MPI engine run on Et 95 gasoline and Eth 100\% ethyl alcohol

b)

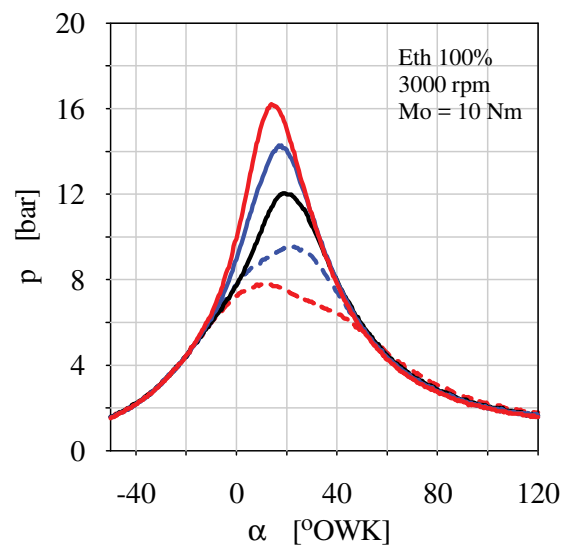

d)

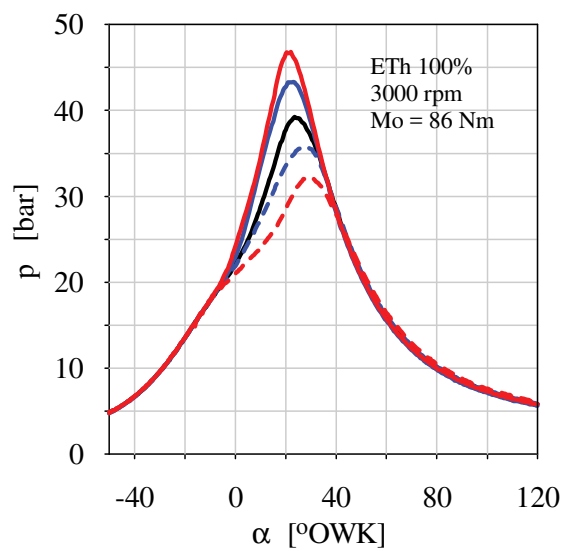

Fig. 10. Comparison of pressure runs in cylinder of the engine run on gasoline and ethanol: rotational speed $3000 \mathrm{rpm}$, minimal load10 Nm and maximal load $86 \mathrm{Nm}$

From the comparison is seen that a lower maximal combustion pressures are accompanied by more late $\mathrm{CR}$ angles of completion of kinetic combustion phase (when the maximal pressure is reached), this phenomenon is more clearly seen in case of low engine loads. For the load of $\mathrm{M}_{\mathrm{o}}$
$=10 \mathrm{Nm}$, in case of the cycles with low pressure it can be seen protracted combustion process accompanied by a higher pressures in more late phases of the combustion. 
The comparison presented in the Fig. 10 shows that in case of two investigated fuels the both runs of combustion with high pressure and with low pressure are similar.

\section{Summary}

Usage of ethyl alcohol to fueling of automotive spark ignition engine results in increased overall efficiency of the engine. Increase of the efficiency occurs in complete range of changes of engine load and rotational speed and amounts to $1.5-2.5 \%$ of absolute values. Further growth of the efficiency can be achieved by increasing compression ratio of the engine, what will enable to take advantage of high knock resistance of ethyl alcohol.

Fueling with ethyl alcohol doesn't result in any significant changes in area of maximal combustion pressure as well as noise level of engine operation, values of average maximal pressures and pressure growths dp are similar. Changes in maximal pressure $p_{\max }$ in successive cycles of engine operation are similar for alcohol and gasoline, and their character is distinctly stochastic.

Quantitative change of maximal pressures defined by mean standard deviation $\sigma_{\mathrm{Pmax}}$ and factor of variability of pressures $s_{p}$ indicate that fluctuations of maximal pressure for gasoline in area of medium and maximal engine loads are higher, what can testify for improvement of smoothness of engine operation run on ethyl alcohol.

In area of low engine loads, when the engine was run on ethyl alcohol, it was observed a worsening of smoothness of engine operation from cycle to cycle. Probably it was caused by reduction of temperature of the charge due to a higher heat of vaporization of ethyl alcohol comparing to gasoline, what had an effect on duration of flame stabilization after ignition of combustible mixture. This issue shall be investigated in course of a further research.

Performed investigations indicate that ethyl alcohol can be used as a pure fuel to modern spark ignition engines. Adaptation scope of the engines to alternating fueling with gasoline and alcohol is small, whereas alcohol fueling can be implemented in selected fleets of cars, or periodically in our climatic zone. It will enable to comply with the National Indicative Targets in range of usage of biofuels and will bring measurable economic benefits due to possibility of usage of water-down alcohols.

\section{Bibliography}

[1] BACZEWSKI, K., KOŁDOŃSKI, T. Paliwa do silników o zapłonie iskrowym. WKiE, Warszawa 2005.

[2] BORYCHOWSKI, M. Produkcja i zużycie biopaliw płynnych w Polsce i na świecie - szanse, zagrożenia, kontrowersje. Roczniki Ekonomiczne Kujawsko-Pomorskiej Szkoty Wyższej w Bydgoszczy. 2012, 5, 39-59.

[3] Biuletyn Urzędu regulacji Energetyki, 2010, 2.

[4] Ethanol Internal Combustion Engines. ETSAP Energy Technology System Analysis Programme. Technology Brief, June 2010.

[5] GMYREK, J. Bioetanol w realizacji NCW w PKN ORLEN S.A., Konferencja „FUEL'S ZOOM - BIOETANOL” Kraków 27-28 kwietnia 2010 r.

[6] KOWALEWICZ, A. Emission characteristics of compression ignition engines fuelled with $\mathrm{RME} / \mathrm{DF}$ and ethanol. Journal of KONES. 2004, 11(1-2).

[7] KOWALEWICZ, A., PAJĄCZEK, Z. Eco-diesel engine with additional injection of ethanol. Archives Combustionis. 2003, 23(3-4).

[8] LÁBAJ, J., BARTA, D., LENHARD, R. CFD simulation of glycerol combustion in diesel engine. Prague. Institute of Thermomechanics AS CR, ISBN 978-80-87012-14-7, 2008, $35-50$.

[9] LARISCH, J., STELMASIAK, Z. Dual fuelling SI engine by mixing alcohol and gasoline. Combustion Engines. 2013, 3.

[10] MCNEIL, J., DAY, P., SIROVSKI, F. Glycerine from biodiesel. The perfect diesel fuel. Process Safety and Environmental Protection - ELSEVIER. 2012, 90, B, 3.

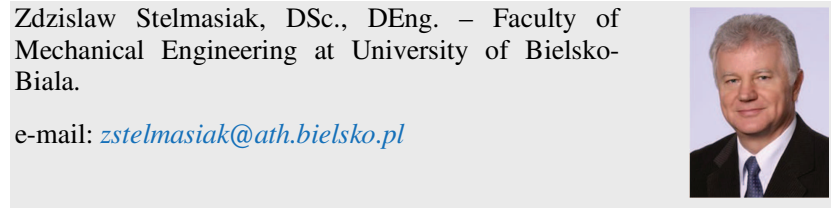

[11] MCNEIL, J. Efficient combustion of glycerol and other low cetane fuels in the diesel engine. The Institution of Diesel and Gas Turbine Engineers publication. Power Eng. 2011.

[12] PAŃCZYSZYN, T. Forum roślin energetycznych. Produkcja biopaliw płynnych - potencjał surowcowy. Poznań, 12.02.2010.

[13] RYCHLIK, A., KIBALCZYC. Ł. Zastosowanie gliceryny do zasilania tłokowych silników wysokoprężnych dużej mocy. Combustion Engines. 2015, 3 .

[14] SEMIKOW, J. Studium dwupaliwowego zasilania silnika o zapłonie iskrowym benzyną i alkoholem. Praca doktorska, ATH Bielsko-Biała, 2012.

[15] STELMASIAK, Z., LARISCH, J., SEMIKOW, J. Some aspects of dual fuelling SI engine with gasoline and alcohol 12th EAEC European Congress Bratislava EAEC. 2009, June 29-July 1.

[16] STELMASIAK, Z., SEMIKOW, J. The possibilities of improvement of spark ignition engine efficiency through dual fueling of methanol and gasoline. Combustion Engines. 2010, 3, 59-67.

[17] STELMASIAK, Z. A new concept of dual fuelled SI engines run on gasoline and alcohol. The Archives of Transport. 2011, 2, 73-85.

[18] STELMASIAK, Z. Applications of alcohols to dual-fuel feeding the spark-ignition and self-ignition engines. Polish Maritime Research. 2014, 3, 86-94.

[19[ WESTCOTT, P.C. Ethanol expansion in the United States. How will the agricultural sector adjust? Economic Research Service. May 2007.

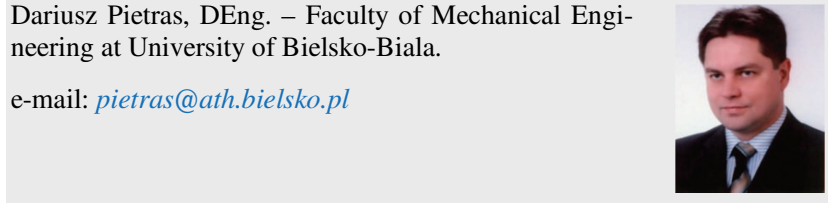

